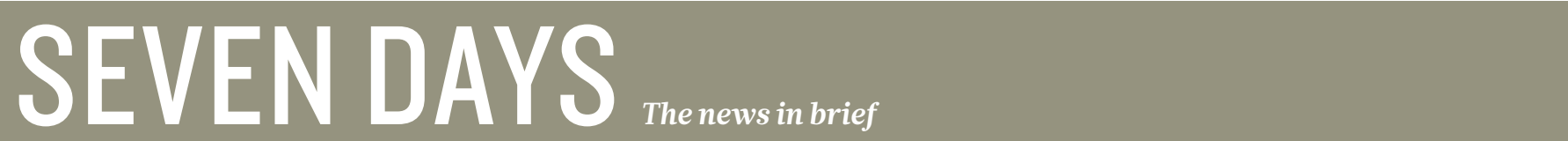

EVENTS

\section{Vostok drilling}

Russian researchers drilling down to the subglacial Lake Vostok, 3,750 metres under Antarctica's ice sheet, were confident that they had reached the lake's surface this week. As Nature went to press, Valery Lukin, director of the Russian Antarctic programme, said that researchers at the site were processing data to check whether they had made the breakthrough. As summer operations in the Antarctic are now ending, the team will soon leave the borehole and will return to do further analysis in December. See go.nature.com/ idwdy8 for more.

\section{Fire damage}

A fire has caused extensive damage to one of Russia's major facilities for nuclear physics. The blaze broke out on 5 February among power cables for the heavy-ion accelerator at the Institute for Theoretical and Experimental Physics in Moscow. No one was injured and damage assessments are ongoing, according to a source at the institute.

FUNDING

\section{French Ivy League}

Five higher-education clusters were selected by the French government on 3 February to get a slice of a $€ 7.7$-billion (US\$10-billion) funding pot intended to create an 'Ivy League' of world-class universities. The institutional alliance Sorbonne Paris City, Sorbonne University and campuses in Toulouse, Aix-Marseille and Saclay will share the pot with the three existing clusters in Bordeaux, Strasbourg and Paris. The windfall marks a break with the country's egalitarian higher-education system and, like other recent cash boosts

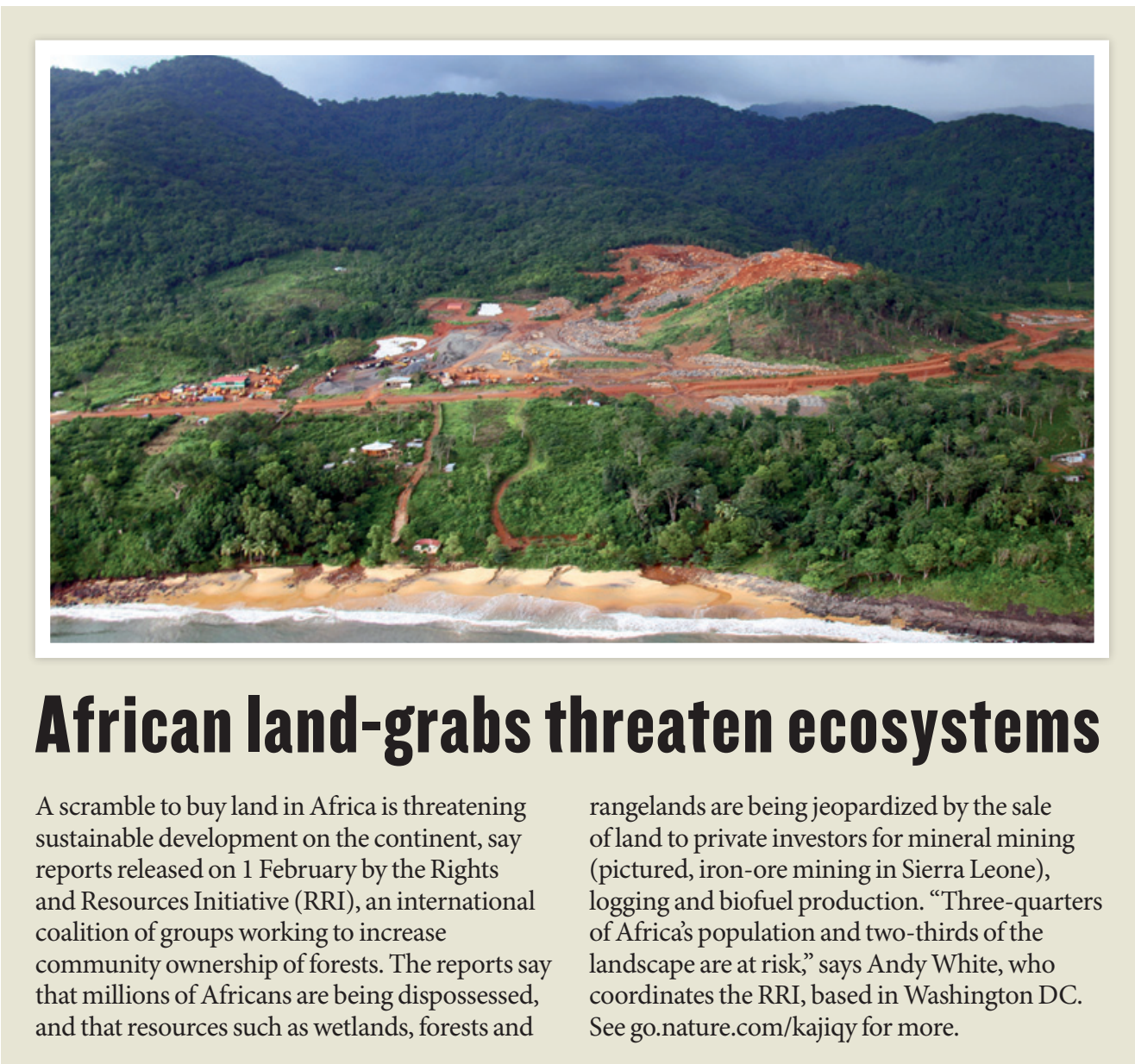

for research, comes from a $€ 35$-billion economic stimulus package announced in 2009 (see Nature 462, 838; 2009).

\section{POLICY}

\section{FDA whistle-blowing}

The way the US Food and Drug Administration (FDA) treats whistle-blowers is attracting congressional scrutiny. Three years ago, agency employees flagged up concerns to the press and to Congress about how medical devices had been approved by officials despite having received poor scientific review. On 25 January, the whistleblowers filed a lawsuit alleging that their e-mails had been secretly monitored, and on 31 January, Senator Charles
Grassley (Republican, Iowa) told FDA commissioner Margaret Hamburg to disclose details of any spying. The FDA told Nature that it does not comment on pending or ongoing litigation.

\section{EU-wide research}

Research agencies,

government departments and centres of excellence in 25 European countries are coordinating their study of neurodegenerative diseases such as Alzheimer's and Parkinson's. On 7 February, they launched the European Union's Joint Programme in Neurodegenerative Disease Research (JPND), the first in a planned series of Joint Programming initiatives to address societal challenges by coordinating and prioritizing research across borders. The JPND will develop treatment, prevention and care strategies. See go.nature.com/aaznbp for more.

\section{Failed Mars probe}

Russia’s Phobos-Grunt spacecraft, which failed to escape Earth orbit in its attempt to reach Mars's moon Phobos last year, was doomed by electronics components not certified for use in space, which in turn led to a computer glitch, according to an official analysis commissioned by the country's space agency, Roscosmos. Its main conclusions were released on 3 February. Once the craft reached orbit, two electronics 
\& chips suffered radiation

崖 damage (which they had not

竞 been designed to withstand),

causing two processors to

reboot and crashing the on-board computer program.

\section{Nuclear restarts}

The International Atomic Energy Agency (IAEA) has endorsed Japan's nuclearreactor 'stress tests' - raising hopes that some of the country's shuttered plants might restart despite public protest. Only 3 of Japan's 54 reactors are currently operating, and reactors that were closed after an earthquake and tsunami struck the Fukushima Daiichi plant last March must pass checks showing that they can withstand similar disasters before they reopen. Reactors at the Ohi plant in Fukui prefecture passed a first round of safety checks in January — but protesters and some nuclear analysts said the tests weren't good enough. IAEA inspectors approved the procedures on 31 January.

\section{Newborn screening}

Minnesota's state health department last week began to destroy its store of bloodspot samples collected from newborn babies. The move follows a November 2011 court ruling that the state must receive informed consent from parents to store

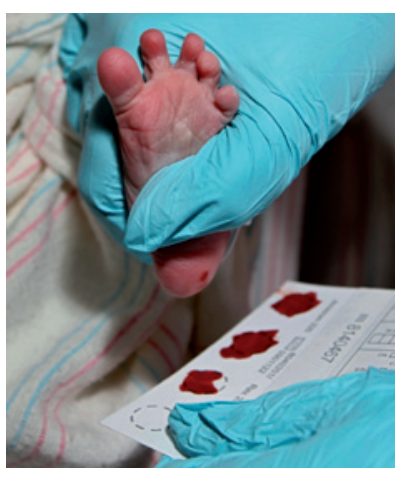

such samples. Blood spots (pictured, being taken from a 1-day-old-baby's heel) from babies are often kept and later used in epidemiological studies or to develop tests for disorders. Biomedical scientists in Minnesota worry that the loss of the samples could harm such research - but campaigners for informed consent say it is more important to preserve parents' trust in the scientific enterprise. See go.nature.com/ hzfxer for more.

\section{RESEARCH \\ Malaria deaths}

Malaria researchers are disputing a high-profile paper that suggests the disease may kill twice as many people worldwide as previously estimated. The research (C. J. L. Murray et al. Lancet 379, 413-431;2012), published on 2 February, puts malaria deaths in 2010 at 1.24 million, whereas the World Health Organization estimates 655,000 . The paper relies on contentious 'verbal autopsies' - interviews with friends and family of the deceased - to compile the death-toll estimate. See go.nature.com/ mpq4gu for more.

\section{BUSINESS \\ Pharma cuts}

Drug giant AstraZeneca announced on 2 February that it would cut 2,200 jobs in research and development, part of a wider cull of 7,300 (about 12\% of its workforce). Following other firms that have abandoned drug-discovery programmes for brain disorders (see Nature 480, 161-162; 2011), the company also said it would end research activity at two sites focused on neuroscience: Södertälje in Sweden and Montreal in Canada. It will keep just 40 or 50 staff in neuroscience, working largely in external collaborations with academia and industry partners.

\section{Cystic fibrosis}

Twenty-three years after scientists announced that they had identified the gene underlying cystic fibrosis, the US Food and Drug Administration has approved a landmark drug that targets a specific mutation in the gene. But ivacaftor (Kalydeco), made

\section{TREND WATCH}

One in five academics in a variety of social-science and business fields say journal editors have asked them to pad their papers with superfluous references to the journal in question, according to a 2 February survey (A. W. Wilhite and E. A. Fong Science 335, 542-543; 2012). Such selfcitations can inflate a journal's impact factor, although Thomson Reuters - which publishes the impact factor - says four-fifths of journals keep self-citations below $30 \%$ (see chart). See go.nature. com/admydy for more.

\section{SELF-CITATIONS IN RESEARCH JOURNALS}

Social-science journals tend to have more self-citations than basic-science journals.

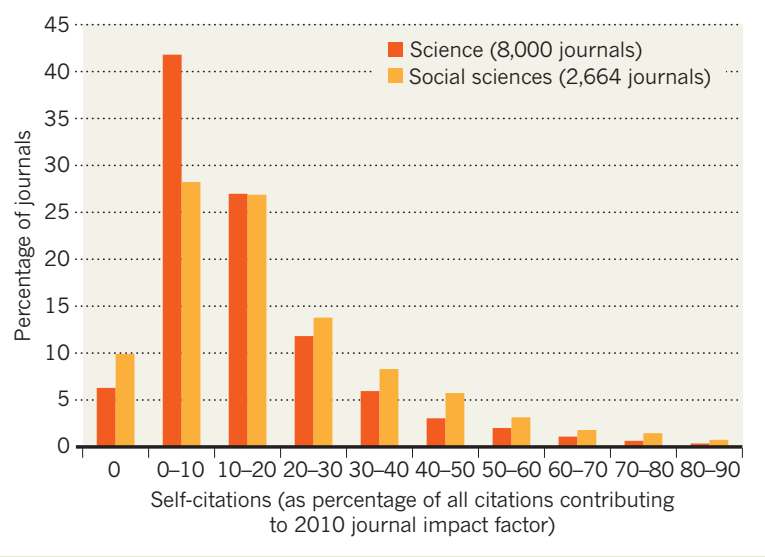

COMING UP

13 FEBRUARY

US researchers find out how much President Barack Obama would like to spend on science next year, in his 2013 budget request.

16-18 FEBRUARY

The 2nd London

Citizen Cyberscience Summit sees researchers and volunteers gather to discuss web-based citizen-science projects, and to think up new ones.

go.nature.com/eggnfg

\section{6-20 FEBRUARY}

The American

Association for the Advancement of Science holds its annual meeting in Vancouver, Canada. www.aaas.org

by Vertex Pharmaceuticals of Cambridge, Massachusetts, is effective in only the $4 \%$ of US patients with cystic fibrosis who have that mutation, and costs US $\$ 294,000$ a year per person. It was approved for sale on 31 January. See page 145 for more.

\section{Satellite contract}

The European Space Agency has signed a $€ 250$-million (US\$327-million) contract for the construction of eight more satellites for Galileo, Europe's global navigation system. The European Commission, which co-funds the network, says that first services should start by 2014 . The winning consortium - OHB System in Bremen, Germany, and partner Surrey Satellite Technology in Guildford, UK — was also contracted to build the first 14 Galileo satellites. The network remains on course for completion (up to 30 satellites) by the end of the decade.

\section{$\rightarrow$ NATURE,COM}

For daily news updates see:

www.nature.com/news 